\title{
Hair Growth Defects of Diabetic and Hypercholesterolemic Wistar Albino Rats and Amelioration of Fish Oil-Treatment
}

Keywords: Hair shaft; Diabetes; Hypercholesterolemia; Fish oil; Amino acids; Glycation end products; Minerals

\begin{abstract}
In this study we estimate the role of fish oil in preserving the hair shaft against dramatic changes of diabetes and or hypercholesterolemia in male Wistar albino rats. Forty male Wistar albino rats weighing approximately $100 \mathrm{~g}$ body weight were used in the present study. They were arranged into 8 groups; control, fish oil-supplementation (100 mg/ $\mathrm{kg}$ every other day), diabetes (streptozotocin $40 \mathrm{mg} / \mathrm{kg}$ single dose in citrate buffer $\mathrm{pH} 4.6$ ), hypercholesterolemia (3\% cholesterol), diabetes \& hypercholesterolemia, diabetes and or hypercholesterolemia \& fish oil. After 12 weeks of treatment, the animals were sacrificed by lightly anesthetize with ether and decapitated. Their hair shafts were shed from their dorsal abdomen. They were subjected for scanning electron microscopy and assessments of amino acids, minerals, and keratin and protein carbonylation and glycation end product. The finding revealed apparent reduction of hair shaft thickness, alterations of some essential and non-essential amino acids and increase of protein carbonylation and glycation end product as well as keratin formation. Fish oil-treatment ameliorates the morphological structure and amino acids contents as well as reduces the formation of glycation end products and restores the loss of keratin. The authors finally concluded that fish oil contain n-3 fatty acid which have antioxidant property as well as required for regeneration of epidermal layers facilitate formation of hair shaft.
\end{abstract}

\section{Introduction}

The hair shaft is a highly keratinized tissue outgrowth from the hair follicle. It is formed of cortex and medulla. The periphery of cortex outlined by a cuticular layer of flattened cells. The hair shaft is composed mainly of hair keratins [1]. Little of studies are concerned with the effects of diabetes and or hypercholesterolemia in skin and hair follicle growth. Researchers are still figuring the close association between diabetes and changes in cellular cholesterol levels as well as the causes of obesity and dyslipidemia [2]. Diabetes mellitus is a heterogeneous group of disorders characterized by chronic hyperglycemia and deficiency in the production and secretion or action of insulin, which leads to severe complications. Obesity and diabetes are considered chronic inflammatory diseases, largely due to the inflammatory cells in white adipose tissue including macrophages [3], B cells [4] and eosinophils [5]. These cells may interact directly through cell-cell contact, directly by releasing cell mediators within adipose tissue. Skin of diabetic rats was found to show apparent thinning of epidermis [6] and dermis followed by a significant numerical reduction of skin mast cells [7], and a decrease in the expression of extracellular matrix components laminin, fibronectin and collagen [8]. Diabetes exhibited decreases in basal cell proliferation, epidermal DNA and stratum corneum turnover [9]. Alopecia areata is one of the hair disease affected by the depletion of
Nutrition and Health

\section{Hassan IH El-Sayyad ${ }^{1 *}$, Mohamed E. Abdraboh ${ }^{1}$ and Ahmad MA Aljebali²}

${ }^{1}$ Department of Zoology, Faculty of Science, Mansoura University, Egypt

${ }^{2}$ Department of Zoology, Faculty of Science, Omar Al Mukhtar University, Bayda, Libya

\section{*Address for Correspondence}

Hassan IH El-Sayyad, Department of Zoology, Faculty of Science, Mansoura University, Mansoura, Egypt, Tel: 0020502254850; E-mail: elsayyad@mans.edu.eg

Submission: 28 July 2015

Accepted: 17 August 2015

Published: 21 August 2015

Copyright: (c) $2015 \mathrm{El}$-Sayyad $\mathrm{HIH}$, et al. This is an open access article distributed under the Creative Commons Attribution License, which permits unrestricted use, distribution, and reproduction in any medium, provided the original work is properly cited.

insulin secretion and vitamin D synthesis [10]. Hypercholesterolemia was found to be associated with an elevated risk of psoriasis [11]. Also, increased glycated nail proteins was recorded in diabetic patients [12], Cholesterol accumulation in the skin of atherosclerotic patients was found to derive from the plasma lipoprotein B [13].

Supplementation of diets rich in omega 3 fatty acids, specifically eicosapentaenoic acid (EPA) and docosahexaenoic acid (DHA) were found to decrease body fat accumulation in patients [14] and experimental animals $[15,16]$ as well as exerted local cutaneous antiinflammatory and antiproliferative metabolites with apparent therapeutic potential in inflammatory skin disorders [17]. Different diseases such as rheumatoid arthritis, psoriasis, lupus erythematosus and multiple sclerosis [18] are improved by fish oil-eicosapentaenoic acid (EPA) and docosahexaenoic acid (DHA) - supplementation [19]. There is no available work concerning fish oil and hair structure and function of diabetic and or hypercholesterolemic.

Reviewing of literature, there is no available work touched this subject of study. The present work aims to illustrate the comparative effects of diabetic and or hypercholesterolemia on hair structure and function and the capacity of amelioration caused by fish oilsupplementation.

\section{Materials and Methods}

Uses of experimental animals were controlled by the quality control and bioethical committee of Mansoura University

\section{Induction of diabetes}

Experimental diabetes mellitus was induced by a single intraperitoneal injection of streptozotocin $(40 \mathrm{mg} / \mathrm{kg})$ in citrate buffer $(0.05 \mathrm{M})$ ( $\mathrm{pH} 4.5)$ [20]. Rats were fed on standard diet for 12 weeks. Control animals were treated with physiological saline as vehicle. Hyperglycemia was verified by measuring the blood glucose more than $200-240 \mathrm{mg} / \mathrm{dL}$. 
Citation: El-Sayyad HIH, Abdraboh ME, Aljebali AMA. Hair Growth Defects of Diabetic and Hypercholesterolemic Wistar Albino Rats and Amelioration of Fish Oil-Treatment. J Nutri Health. 2015;1(1): 6.

\section{Induction of hypercholesterolemia}

The experimental group was fed a hypercholesterolemic diet composed of $3 \%$ cholesterol and $15 \%$ cocoa butter and $0.2 \%$ cholic acid and $0.2 \%$ thiouracil [21]. Feeding on hypercholesterolemic diet was carried out for 12 weeks. The control group was supplied a standard diet free from atherogenic components.

\section{Fish oil-supplementation}

Fish oil (Menhaden, highest purity) was used in the experimental work. Each rats received oral doses of $100 \mathrm{mg} / \mathrm{kg}$ body weight every other day during the period of treatment.

\section{Experimental work}

Forty fertile male albino rats with body weight of 100-110 g They were obtained from Breading Farm, Ministry of Health, and Giza, Egypt. Rats were fed on standard diet and water was allowed ad libitum throughout the experimental period. They were housed in good ventilation with $12 \mathrm{~h}$ light and dark cycle. Male rats were fed on hypercholesterolemic diet for 12 weeks. Diabetes was carried out and animals allowed standard diet for the similar period of cholesterol fed rats. Rats were arranged into eight groups $(n=5)$ such as Control (C), fish oil-supplementation (F), hypercholesterolemicgroup $(\mathrm{H})$, hypercholesterolemic and fish oil-treatment (HF), diabetic-group (D), diabetes and fish oil-treatment (DF), combined hypercholesterolemic and diabetic group (HD) and combined diabetes and hypercholesterolemic and fish oil-treatment (HDF). At the end of treatment, male rats of both control and experimental groups were subjected to light anesthesia by chloroform, sterile their dorsal abdominal skin and shaving their hair by sharp sterile razors. The rats were refreshed for extra observations. The dorsal abdominal hairs were collected and subjected for the following investigations:

\section{Scanning electron microscopy}

Basal hair shafts were incised from dorsal abdominal surface of both control and experimental groups and dehydrated in ascending grades of ethyl alcohol. The specimens were allowed to dry in a carbon dioxide critical point apparatus, mounted in stubs and coated with gold by low voltage DC sputtering and investigated under scanning electron microscope JOEL5300 JSM (musashino 3-chome akishima Tokyo 196-8558, Japan).

\section{Determination of hair amino acid contents}

Hair amino acids contents of both control and experimental groups were hydrolysed by $6 \mathrm{M}$ hydrochloric acid. The samples were washed in hot dilute detergent solution at neutral $\mathrm{pH}$ and rinsed in warm tap water and then distilled water. Any pulpy protein in the column was squeezed out and extracted several times with petroleum ether, followed by $95 \%$ ethyl alcohol and allowed to dry in a watch glass. The samples were dried under vacuum, redissolved in 10 to $100 \mu \mathrm{l} 0.2 \mathrm{M}$ sodium citrate buffer, $\mathrm{pH} 2.0$ and loaded on the amino acid analyzer equipped with a cation exchange column (Amersham Pharmacia Biotech), which was equilibrated in $0.2 \mathrm{M}$ sodium citrate buffer, $\mathrm{pH}$ 2.0. Detection of the modified amino acids was achieved calorimetrically at $440 \mathrm{~nm}$ for proline and hydroxyproline and at 570 $\mathrm{nm}$ for all other amino acids [22].

\section{Determination of iron, zinc and calcium contents}

Hair shaft samples were collected from the dorsal abdomen of both control and experimental groups, washed thoroughly with distilled water and weighed. They were dried and mixed well by using chloroform methyl mixture 2:1 for lipid extraction. A known weighed of sample per each experimental group was digested by $1 \mathrm{~mL}$ of nitric acid at highest purity and diluted with $4 \mathrm{~mL}$ bi-distilled water. Iron, zinc and calcium were measured by atomic absorption spectrometry [23].

\section{Keratin 18 contents}

Rat hair keratin 18 was determined by Elisa kit (Wuhan USCN Business Co., Ltd., catalogue no. SEB231Ra). Specific antibody to Keratin 18 (KRT18) is used. TMB substrate solution is added and the reaction is terminated by the addition of sulphuric acid solution and the color change is measured spectrophotometrically at a wavelength of $450 \mathrm{~nm} \pm 10 \mathrm{~nm}$. The concentration of Keratin 18 (KRT18) is then determined by comparing the O.D. of the samples to the standard curve.

\section{Protein carbonylation and glycation end products}

Protein carbonylation was assessed by determination of the reactive carbonyl groups with 2, 4-dinitrophenylhydrazine (DNPH) to form protein-bound 2, 4-dinitrophenylhydrazones by using the Cells Biolabs kit (Catalogue No STA-317). The amount of proteinhydrazone produced is quantified spectrophotometrically at an absorbance between 360-385 $\mathrm{nm}$ and the carbonyl content can be the standard protein concentration. AGE products contain CML, pentosidines and other AGE structures. Advanced glycation end product (AGE) is determined using Cell Biolabs, Inc kit (Catalogue No STA-317). The quantity of AGE adduct in protein samples is determined by comparing its absorbance with that of a known advanced glycation end product and bovine serum albumin (AGEBSA) standard curve.

\section{Results}

\section{Morphometry and scanning electron microscopy}

Diabetes and or hypercholesterolemia were found to cause apparent reduction of hair shaft and improved after combined treatment with fish oil but still below the control level (Figure 1 and Figure 2). The outer cornified leaflet sheets were comparatively less organized in diabetic and or hypercholesterolemia. Increased deformity of hair shaft was detected in combined diabetes and hypercholesterolemia where thinning appeared and ruptured. Fish oil-treatment restored its ordinary structures but was still lacked normal leaflet sheet arrangement (Figure 1C-1HDF).

\section{Hair amino acid contents}

From Table 1, the essential amino acids Histidine, Isoleucine, Leucine and Methionine were decreased in diabetes and or hypercholesterolemia and improved after fish oil-treatment. However, Phenylalanine, Threonine and Valine were less affected. Non-essential amino acids Aspartic acid, Cysteine, Glutamic, Glycine and Tyrosine were decreased. Cysteine showed apparent reduction in diabetes and or hypercholesterolemia more than the other amino acids. Fish oil treatment of the diseased experimental groups restored almost their contents of their losing amino acids. 
Citation: El-Sayyad HIH, Abdraboh ME, Aljebali AMA. Hair Growth Defects of Diabetic and Hypercholesterolemic Wistar Albino Rats and Amelioration of Fish Oil-Treatment. J Nutri Health. 2015;1(1): 6.
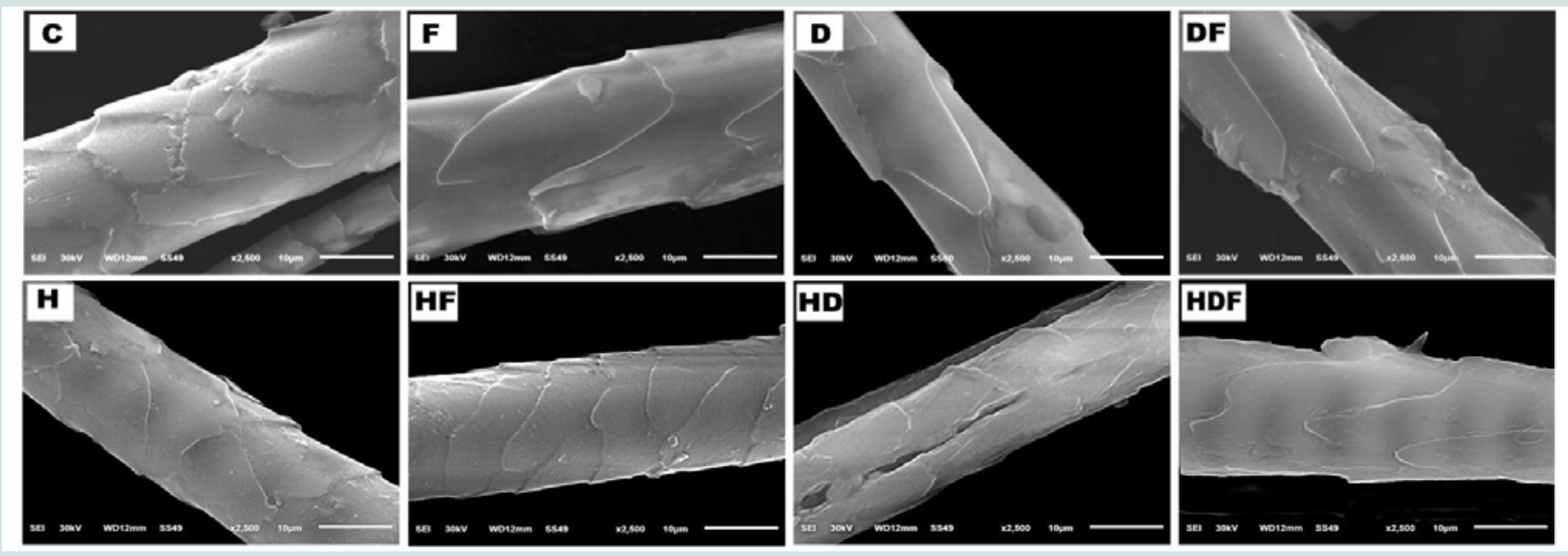

Figure 1: Scanning electron microscope of hair of diabetic and hypercholesterolemic male rats. C: Control; F: Fish oil; D: Diabetes; DF: Diabetes \& Fish oil; H: Hypercholesterolemia; HF: Hypercholesterolemia \& Fish oil; HD: Hypercholesterolemia \& Diabetes; HDF: Hypercholesterolemia \& Diabetes \& Fish oil.

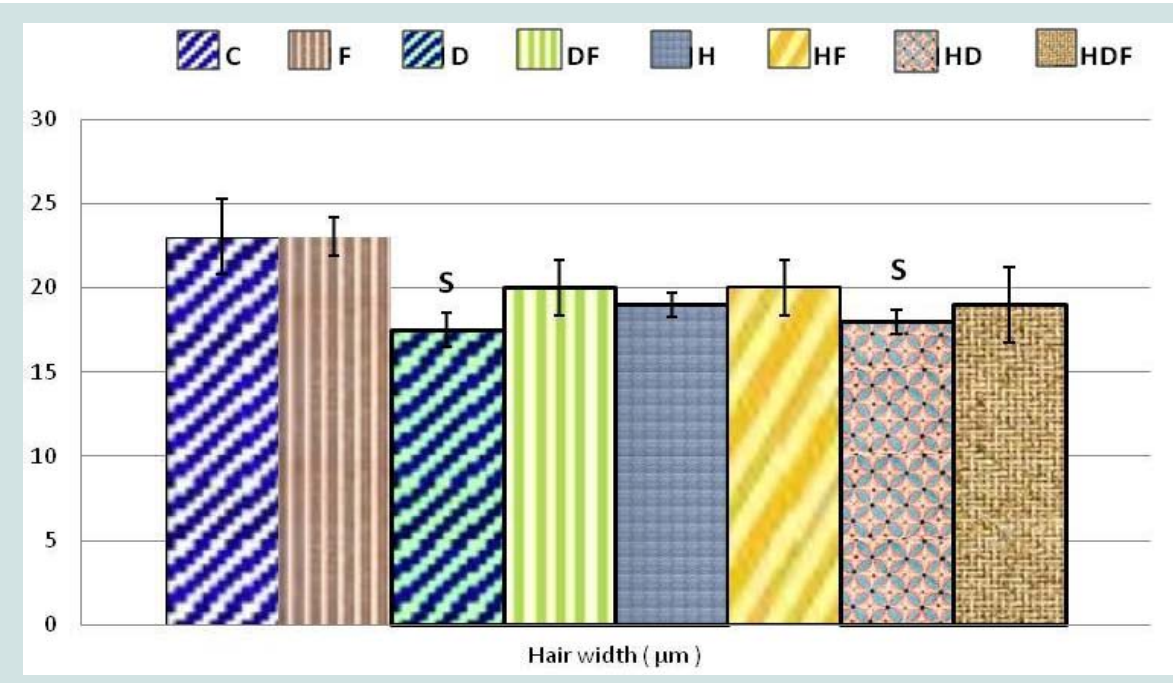

Figure 2: Hair thickness of diabetic and hypercholesterolemia male rats. Each result represent the mean $\pm S E(n=5)$. S, significant at $P<0.05$.Abbreviations; C: Control; F: Fish oil; D: Diabetes; DF: Diabetes Fish oil; H: Hypercholesterolemia; HF: Hypercholesterolemia Fish oil; HD: Hypercholesterolemia Diabetes; HDF: Hypercholesterolemia Diabetes Fish oil.

\section{Iron, zinc and calcium contents}

The assayed iron and zinc were decreased in experimental diabetes and or hypercholesterolemic groups. However, calcium ions was highly susceptible and in the diseased groups. Fish oil-treatment improves hairs mineral contents but was still below the normal value (Table 1).

\section{Keratin, carbonylation and glycation end product}

Diabetes and or hypercholesterolemia were found to decrease the hair shaft content of keratin 18 and increase protein carbonylation and glycation end product. Fish oil-treatment improved the keratin content and decreased the protein carbonylation and glycation end product (Table 2).

\section{Discussion}

Diabetes and or hypercholesterolemia interfered with hair shaft growth causing apparent reduction and deformation especially in diabetic and hypercholesterolemic group. Similar finding of reducing hair follicle diameter was reported in diabetic patients [24].

Similar findings of hair deformation were reported by Klam et al. who mentioned apparent reduction of both hair pulp and hair shaft in diabetic patients [24]. Alopecia is concerned with metabolic disorder such as diabetes [25] and dyslipidemia [26]. Also, diabetic mice possessed a reduction in both the epidermal proliferation and stratum corneum water content with apparent loss of the stratum corneum barrier function [9].

Also, hypercholesterolemia was found to increase of fatty tissue in the subcutaneous layer which led to alopecia [27]. Studying hair growth in deficient transgenic knockout (Epi-Insig-DKO) mice revealed normal pattern of hair growth at 7 day-old followed by deformation of hair associated with increase of cholesterol the promoter of increase in 3-hydroxy-3-methylglutaryl coenzyme A reductase protein [28]. 
Citation: El-Sayyad HIH, Abdraboh ME, Aljebali AMA. Hair Growth Defects of Diabetic and Hypercholesterolemic Wistar Albino Rats and Amelioration of Fish Oil-Treatment. J Nutri Health. 2015;1(1): 6.

\begin{tabular}{|c|c|c|c|c|c|c|c|c|c|}
\hline & \multicolumn{8}{|c|}{$\mu \mathrm{mol} / 100 \mathrm{mg}$} & \multirow[b]{2}{*}{ F Test } \\
\hline & C & $\mathbf{F}$ & D & DF & $\mathbf{H}$ & HF & HD & HDF & \\
\hline \multicolumn{10}{|c|}{ Essential AA } \\
\hline Histidine & $0.81 \pm 0.08$ & $* 0.88 \pm 0.10$ & ${ }^{* *} 0.37 \pm 0.07$ & $* 0.73 \pm 0.1$ & $* * 0.48 \pm 0.09$ & ${ }^{*} 0.78 \pm 0.09$ & ${ }^{* *} 0.32 \pm 0.08$ & ${ }^{* *} 0.5 \pm 0.06$ & 75.161 \\
\hline Isoleucine & $3.23 \pm 0.20$ & $* 3.23 \pm 0.28$ & $* * 2.71 \pm 0.19$ & $* 3.01 \pm 0.22$ & $* * 2.83 \pm 0.15$ & $* 3.12 \pm 0.3$ & $* * 2.63 \pm 0.20$ & $* 2.86 \pm 0.36$ & 30.966 \\
\hline Leucine & $5.30 \pm 0.30$ & $* 4.94 \pm 0.4$ & $* * 4.5 \pm 0.30$ & $* 4.86 \pm 0.5$ & $* * 4.53 \pm 0.30$ & $* 4.9 \pm 0.56$ & $* * 4.39 \pm 0.44$ & $* 4.83 \pm 0.45$ & 25.517 \\
\hline Methionine & $0.88 \pm 0.14$ & ${ }^{*} 0.71 \pm 0.18$ & ${ }^{* *} 0.26 \pm 0.08$ & ${ }^{* *} 0.51 \pm 0.12$ & ${ }^{* *} 0.33 \pm 0.09$ & ${ }^{* *} 0.54 \pm 0.15$ & ${ }^{* *} 0.21 \pm 0.07$ & ${ }^{* *} 0.35 \pm 0.11$ & 12.002 \\
\hline Phenylalanine & $1.62 \pm 0.47$ & $* 1.62 \pm 0.34$ & $* 1.54 \pm 0.32$ & $* 1.59 \pm 0.39$ & $* 1.56 \pm 0.44$ & ${ }^{*} 1.62 \pm 0.33$ & $* 1.51 \pm 0.36$ & $* 1.58 \pm 0.2$ & 2.619 \\
\hline Threonine & $7.92 \pm 0.40$ & $* 7.95 \pm 0.42$ & $* * 7.23 \pm 0.20$ & $* 7.81 \pm 0.43$ & $* 7.61 \pm 0.30$ & $* 7.88 \pm 0.41$ & $* * 7.05 \pm 0.25$ & $* 7.77 \pm 0.36$ & 42.529 \\
\hline Valine & $6.76 \pm 0.340$ & $* 6.79 \pm 0.44$ & $* * 6.09 \pm 0.26$ & $* 6.47 \pm 0.44$ & $* * 6.16 \pm 0.28$ & ${ }^{*} 6.71 \pm 0.49$ & $* * 6.01 \pm 0.23$ & $* 6.39 \pm 0.44$ & 56.733 \\
\hline \multicolumn{10}{|c|}{ Non-Essential AA } \\
\hline Alanine & $5.6 \pm 0.60$ & $* 5.63 \pm 0.56$ & *5.36 \pm 0.44 & $* 5.55 \pm 0.58$ & $* 5.38 \pm 0.49$ & $* 5.57 \pm 0.4$ & $* 5.24 \pm 0.34$ & *5.48 \pm 0.55 & 5.309 \\
\hline Arginine & $7.65 \pm 0.39$ & $* 7.79 \pm 0.34$ & $* 7.46 \pm 0.32$ & *7.61士0.39 & $* 7.55 \pm 0.44$ & $* 7.63 \pm 0.33$ & $* 7.4 \pm 0.36$ & $* 7.55 \pm 0.29$ & 26.414 \\
\hline Aspartic & $5.54 \pm 0.26$ & $* 5.57 \pm 0.28$ & $* * 4.99 \pm 0.19$ & $* 5.3 \pm 0.22$ & $* * 5.05 \pm 0.15$ & $* 5.55 \pm 0.30$ & $* * 4.93 \pm 0.20$ & $* 5.24 \pm 0.36$ & 2.208 \\
\hline Cysteine & $10.36 \pm 0.80$ & ${ }^{*} 10.51 \pm 1.01$ & $* * 4.69 \pm 0.73$ & $* * 8.12 \pm 0.5$ & $* * 5.55 \pm 0.75$ & $* * 8.91 \pm 0.45$ & $* * 4.05 \pm 0.78$ & $* * 6.85 \pm 0.6$ & 2594.5 \\
\hline Glutamic & $13.51 \pm 0.28$ & $* 13.58 \pm 0.34$ & ${ }^{* *} 12.89 \pm 0.27$ & $* 13.44 \pm 0.44$ & $* * 12.95 \pm 0.26$ & ${ }^{*} 13.55 \pm 0.42$ & $* * 12.82 \pm 0.27$ & $* 13.44 \pm 0.47$ & 31.022 \\
\hline Glycine & $6.70 \pm 0.30$ & $* 6.33 \pm 0.44$ & $* * 5.92 \pm 0.39$ & $* 6.28 \pm 0.45$ & $* * 5.95 \pm 0.34$ & ${ }^{*} 6.29 \pm 0.4$ & $* * 5.89 \pm 0.35$ & ${ }^{* *} 6.01 \pm 0.32$ & 7.790 \\
\hline Proline & $8.21 \pm 0.59$ & $* 8.25 \pm 0.54$ & $* 7.86 \pm 0.48$ & $* 8.14 \pm 0.42$ & $* 7.89 \pm 0.49$ & $* 8.17 \pm 0.53$ & $* 7.59 \pm 0.39$ & $* 8.04 \pm 0.52$ & 14.94 \\
\hline Serine & $11.63 \pm 0.36$ & $* * 12.39 \pm 0.37$ & $* * 10.72 \pm 0.44$ & $* 11.38 \pm 0.46$ & $* * 10.92 \pm 0.26$ & $* 11.42 \pm 0.49$ & $* * 10.57 \pm 0.50$ & *11.21士0.53 & 72.362 \\
\hline Tyrosine & $2.55 \pm 0.40$ & $* 2.61 \pm 0.54$ & $* * 1.56 \pm 0.42$ & $* 2.44 \pm 0.32$ & $* * 1.77 \pm 0.28$ & $* 2.51 \pm 0.39$ & $* * 1.48 \pm 0.33$ & $* 1.87 \pm 0.44$ & 340.93 \\
\hline \multicolumn{10}{|c|}{ Minerals } \\
\hline IRON & $2.05 \pm 0.4$ & $* 2.26 \pm 0.6$ & $* 1.84 \pm 0.4$ & $* 1.91 \pm 0.2$ & $* 1.86 \pm 0.13$ & $* 2.03 \pm 0.4$ & $* 1.83 \pm 0.11$ & $* 1.88 \pm 0.3$ & 62.067 \\
\hline ZINC & $23.52 \pm 1.7$ & $* 23.69 \pm 1.88$ & $* * 19.96 \pm 1.3$ & $* 21.29 \pm 1.9$ & $* * 20.22 \pm 1.4$ & *21.39 2.1 & $* * 19.28 \pm 1.33$ & 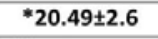 & 3607.4 \\
\hline Calcium & $101.05 \pm 2.1$ & $* 103.69 \pm 3.2$ & $* * 108.25 \pm 2$ & $* * 110.3 \pm 2.3$ & **109.74士.1.7 & $* * 111.57 \pm 1.3$ & $* * 108.44 \pm 1.8$ & $* * 110.08 \pm 2.1$ & 7.952 \\
\hline
\end{tabular}

Table 1: Role of fish oil on amino acids and minerals contents of hair of diabetic and/or hypercholesterolemic male rats.

Each result represents the mean \pm SE $(n=5)^{*}$, Non-significant at $P<0.05^{\star *}$, Significant at $P<0.05$. Abbreviations: C: Control; F: Fish oil; D: Diabetes; DF: Diabetes Fish oil; H: Hypercholesterolemia; HF: Hypercholesterolemia Fish oil; HD: Hypercholesterolemia Diabetes; HDF: Hypercholesterolemia Diabetes Fish oil.

\begin{tabular}{|l|c|c|c|c|c|c|c|c|c|}
\hline & C & F & D & DF & H & HF & HD & HDF & F Test \\
\hline Keratin $18(\mathrm{ng} / 100 \mathrm{mg})$ & $6.86 \pm 0.24$ & $* 7.05 \pm 0.34$ & $* * 6.15 \pm 0.29$ & $* * 6.4 \pm 0.24$ & $* * 6.29 \pm 0.19$ & $* * 6.43 \pm 0.18$ & $* * 6.01 \pm 0.33$ & $* * 6.33 \pm 0.26$ & 206.2 \\
\hline Protein carbonylation $(\mathrm{nmol} / \mathrm{mg})$ & $1.66 \pm 0.15$ & $* 1.55 \pm 0.2$ & $* * 2.67 \pm 0.32$ & $* * 2.16 \pm 0.18$ & $* * 2.42 \pm 0.25$ & $* * 1.94 \pm 0.14$ & $* * 2.84 \pm 0.24$ & $* * 2.44 \pm 0.19$ & 353.5 \\
\hline Glycation end product $(\mu \mathrm{g} / 100 \mathrm{mg})$ & $1.96 \pm 0.2$ & $* 1.93 \pm 0.25$ & $* * 2.61 \pm 0.33$ & $* 2.18 \pm 0.23$ & $* * 2.46 \pm 0.14$ & $* 2.05 \pm 0.18$ & $* * 2.88 \pm 0.25$ & $* * 2.43 \pm 0.24$ & 226 \\
\hline
\end{tabular}

Table 2: Role of fish oil on keratin, protein carbonylation and Glycation end product contents of hair of diabetic and or hypercholesterolemic male rats. Each result represents the mean \pm SE. $(n=5)^{\star}$, Non-significant at $P<0.05^{* *}$, Significant at $P<0.05$. Abbreviations: C: Control; F: Fish oil; D: Diabetes; DF: Diabetes Fish oil; H: Hypercholesterolemia; HF: Hypercholesterolemia Fish oil; HD: Hypercholesterolemia Diabetes; HDF: Hypercholesterolemia Diabetes Fish oil.

Concerning minerals, the hair zinc content showed apparent decrease in experimental diabetes and or hypercholesterolemic groups. Similar findings of altered zinc and iron level in hair follicles were reported by Afridi et al. in diabetic patients [29]. Similar findings of decreased hair $\mathrm{Zn}$ content was reported by Kazi et al. in blood and scalp-hair samples of diabetic patients as compared to control subjects [30]. Iron represent of the main element of hair growth. The present work revealed a decrease in iron content of diabetes and or hypercholesterolemia.

Similar findings were mentioned by Moeinvaziri et al. in women with diffuse telogen hair loss [31]. The author exhibited apparent depletion of ferritin level and trasferrin saturation comparing with that of normal hair growth. Serum ferreting levels was found to be closely related to vitamin D2 were markedly decreased in females with either chronic telogen effluvium or hair loss [32]. Feeding Wistar rats on a high-fat/high-energy (HF/HE) diet led to 3.5-fold depletion of hepcidin mRNA than in control which attributed to apparent reduction of iron accumulation and transferrin saturation [33].

Also, diabetes and or hypercholesterolemia showed markedly increase of calcium ions in diabetic and or hypercholesterolemia in comparison with the control.

Hair calcium level was found to be increased in patient with arterial stiffness (vascular calcification) and was influenced by increase of low density lipoprotein and cholesterol level [34].

Park et al. attributed the increase of hair calcium content to the intercellular calcium content associated with systemic diseases such as coronary artery diseases which may be correlated with low calcium intake and low bone mineral density [35].

From the present findings diabetes and or hypercholesterolemia exhibited apparent depletion of the essential amino acids -histidine, isoleucine, leucine and methionine- and non-essential amino acids -aspartic acid, cysteine, glutamic, glycine and tyrosine. These amino acids play great roles in differentiation of epidermis and hair pulp. Depletion of it seemed too interfered with epidermal cell turn over and hair growth.

Rashaid et al. reported that the nonessential amino acids Gly and Glu, and the essential amino acid Ile were markedly increased in the 
Citation: El-Sayyad HIH, Abdraboh ME, Aljebali AMA. Hair Growth Defects of Diabetic and Hypercholesterolemic Wistar Albino Rats and Amelioration of Fish Oil-Treatment. J Nutri Health. 2015;1(1): 6.

ISSN: 2469-4185

scalp hair of diabetic patients comparing to the control subjects [36]. The index of glycated protein and cysteine in scalp hair was markedly increased in hypercholesterolemic mice, diabetic rat and diabetic patients [37].

Also, increased carbonylation and glycation of proteins in hair shaft appeared to be resulted from the dramatic changes associated with diabetes and or hypercholesterolemia.

In diabetic patients, there was a detected increased incidence of conjugated fructose and lysine forming glycated furosine [38]. There is a hypothesis that glycation of hair protein might provide insight into blood glucose levels over a period of several months to one year [39].

In vitro glycation of hair was found to possess a reduction of hair protein content and breaking strength and increased advanced glycation end product [40].

From the present findings, fish oil-treatment seemed to be improved the morphological structures and thickness of the hair shaft as well as restored their zinc, iron and calcium content, almost normal amino acid content and inhibit the formation of protein carbonylation and glycation end product. The keratin content retained almost to its normal level.

Taking in consideration, the hair follicle cells showed a higher capacity of regeneration. Their active metabolism requires continuous energy and nutrient supply. In clinical trials eicosapentaenoic acid (EPA) and docosahexaenoic acid (DHA) in the form of fish oils are not interconvertible in the human body and are essential components of all cell membranes [41]. The amelioration of fish oil resulted from its contents of n-3 fatty acids such as docosahexaenoic acid and eicosapentaenoic acid which have direct effects on reducing the inflammatory state by reducing IL-6, TNF- $\alpha$, CRP and many other factors [42].

Also, fish oil was found to prevent lipid peroxidation products and possess potent immune modulation effects and therapeutic benefits in animal disease models or human diseases [43]. There was apparent balance between the n-3 and n- 6 series of essential fatty acids (EFAs) which is important for homeostasis and normal growth in humans. Alopecia and depigmentation of hair were reported in an essential fatty acid (EFA) deficient 19-year-old man [44].

The oxidative formation of $\mathrm{N}$ (epsilon)-(Carboxymethyl) lysine (CML) from glycated proteins was reduced by different antioxidants such as lipoic acid, aminoguanidine, superoxide dismutase, catalase, and particularly vitamin $\mathrm{E}$ and desferrioxamine in diabetic patients [36]. Fish oil (omega 3\&6) supplementation for 6 months-treatment was found to improve hair density and reducing the telogen percentage against hair loss [45].

Finally the author concluded that fish oil supplementation improve the histopathological picture and brain function of rats subjected to diabetes and or hyper cholesterolemia.

\section{References}

1. Rogers MA, Langbein L, Praetzel-Wunder S, Winter H, Schweizer J (2006) Human hair keratin-associated proteins (KAPs). Int Rev Cytol 251: 209-263.

2. Nsiah K, Shang VO, Boateng KA, Mensah FO (2015) Prevalence of metabolic syndrome in type 2 diabetes mellitus patients. Int J Appl Basic Med Res 5: 133-138.

3. Xu H, Barnes GT, Yang Q, Tan G, Yang D, et al. (2003) Chronic inflammation in fat plays acrucial role in the development of obesity- related insulin resistance. J Clin Invest 112: 1821-1830.

4. Winer DA, Winer S, Shen L, Wadia PP, Yantha J, et al. (2011) B cells promote insulin resistance through modulation of $T$ cells and production of patho genic IgG antibodies. Nat Med 17: 610-617.

5. Wu D, Molofsky AB, Liang HE, Ricardo-Gonzalez RR, Jouihan HA, et al. (2011) Eosinophils sustain adipose alternatively activated macrophages associated with glucose homeostasis. Science 332: 243-247.

6. Boric M, Skopljanac I, Ferhatovic L, Jelicic Kadic A, Banozic A, et al. (2013) Reduced epidermal thickness, nerve degeneration and increased painrelated behavior in rats with diabetes type 1 and 2. J Chem Neuroanat 53: 33-40.

7. Carvalho VF, Florim LT, de O Barreto E, Torres RC, Batista MM, et al. (2011) Inhibition of advanced glycation end products by aminoguanidine restores mast cell numbers and reactivity in alloxan-diabetic rats. Eur J Pharmacol 669: 143-148.

8. de F Carvalho V, Campos LV, Farias-Filho FA, Florim LT, Barreto EO, et al (2008) Suppression of allergic inflammatory response in the skin of alloxandiabetic rats: relationship with reduced local mast cell numbers. Int Arch Allergy Immunol 147: 246-254.

9. Sakai S, Endo Y, Ozawa N, Sugawara T, Kusaka A, et al. (2003) Characteristics of the epidermis and stratum corneum of hairless mice with experimentally induced diabetes mellitus. J Invest Dermatol 120: 79-85.

10. Mahamid M, Abu-Elhija O, Samamra M, Mahamid A, Nseir W (2014) Association between vitamin D levels and alopecia areata. Isr Med Assoc J 16: $367-370$

11. Wu S, Li WQ, Han J, Sun Q, Qureshi AA (2014) Hypercholesterolemia and risk of incident psoriasis and psoriatic arthritis in US women. Arthritis Rheumatol 66: 304-310.

12. Kishabongo AS, Katchunga P, Van Aken EH, Speeckaert MM, Lagniau S, et al. (2014) Glycated nail proteins: a new approach for detecting diabetes in developing countries. Trop Med Int Health 19: 58-64.

13. Bouissou H, de Graeve J, Legendre C, Solera ML, Wulfert E, et al. (1982) Skin cholesterol and skin apoprotein B in atherosclerosis. Biomed Pharmacother 36: 159-162.

14. Noreen EE, Sass MJ, Crowe ML, Pabon VA, Brandauer J, et al. (2010) Effects of supplemental fish oil on resting metabolic rate, body composition, and salivary cortisol in healthy adults. J Int Soc Sports Nutr 7: 31.

15. Fickova M, Hubert P, Cremel G, Leray C (1998) Dietary (n-3) and (n-6) polyunsaturated fatty acids rapidly modify fatty acid composition and insulin effects in rat adipocytes. J Nutr 128: 512-519.

16. Baillie RA, Takada R, Nakamura M, Clarke SD (1999) Coordinate induction of peroxisomal acyl-CoA oxidase and UCP-3 by dietary fish oil: a mechanism for decreased body fat deposition. Prostaglandins Leukot Essent Fatty Acids 60: 351-356.

17. Ziboh VA, Miller CC, Cho Y (2000) Metabolism of polyunsaturated fatty acids by skin epidermal enzymes: generation of antiinflammatory and antiproliferative metabolites. Am J Clin Nutr 71: 361S-366S.

18. Simopoulos AP (2002) Omega-3 Fatty acids in inflammation and autoimmune diseases. J Am Col Nutr 21: 495-505.

19. Moghadasian $\mathrm{MH}$ (2008) Advances in dietary enrichment with $\mathrm{N}-3$ fatty acids. Critical Rev Food Sci Nut 48: 402-410.

20. Povoski SP, McCullough PJ, Zhou W, Bell RH Jr (1993) Induction of diabetes mellitus in Syrian golden hamsters using stored equilibrium solutions of streptozotocin. Lab Anim Sci 12: 310-314.

21. Enkhmaa B, Shiwaku K, Katsube T, Kitajima K, Anuurad E, et al. (2005) Mulberry (Morus alba L.) leaves and their major flavonol quercetin 
Citation: El-Sayyad HIH, Abdraboh ME, Aljebali AMA. Hair Growth Defects of Diabetic and Hypercholesterolemic Wistar Albino Rats and Amelioration of Fish Oil-Treatment. J Nutri Health. 2015;1(1): 6.

3-(6-malonylglucoside) attenuate atherosclerotic lesion development in LDL receptor-deficient mice. J Nutr 135: 729-734.

22. Niece RL, Ericsson LH, Fowler AV, Smith AJ, Speicher DW, et al. (1991) Amino acid analysis and sequencing: What is state-of-the-art?" In: Methods in Protein Sequence Analysis, Basel, Switzerland, Birkhauser Verlag 133-141.

23. Scancar J, Milacic R, Benedik M, Bukovec P (2000) Determination of trace elements and calcium in bone of the human iliac crest by atomic absorption spectrometry. Clin Chim Acta 293: 187-197.

24. Klam WP, Roeder LM, Rosenbrough RH, Heald FP (1983) Scalp hair morphology in normal and diabetic children and adolescents. J Adolesc Health Care 4: 91-93.

25. Faiyazu-Az-Ui-Haque M, Zaidi SH, Al-Sanna N, Alswaid A, Momenah T, et al. (2009) A novel missense and a recurrent mutation in SCL2A10 gene of patients affected with arterial tortuosity syndrome. Atherosclerosis 203: 466471.

26. Matilainen V, Koskela P, Keinänen-Kiukaanniemi S (2000) Early androgenetic alopecia as a marker of insulin resistance. Lancet 356: 1165-1166.

27. Bukhari I, Al Mulhim F, Al Hoqail R (2004) Hyperlipidemia and lipedematous scalp. Ann Saudi Med 24: 484-485.

28. Evers BM, Farooqi MS, Shelton JM, Richardson JA, Goldstein JL, et al (2010) Hair growth defects in insig-deficient mice caused by cholesterol precursor accumulation and reversed by simvastatin. J Invest Dermatol 130: 12371248.

29. Afridi HI, Kazi TG, Talpur FN, Brabazon D (2015) Evaluation of trace and toxic elements in the samples of different cigarettes and their impact on human health of Irish diabetes mellitus patients. Clin Lab 61: 123-140.

30. Kazi TG, Afridi HI, Kazi N, Jamali MK, Arain MB, et al. (2008) Copper chromium, manganese, iron, nickel, and zinc levels in biological samples of diabetes mellitus patients. Biol Trace Elem Res 122: 1-18.

31. Moeinvaziri M, Mansoori P, Holakooee K, Safaee Naraghi Z, Abbasi A (2009) Iron status in diffuse telogen hair loss among women. Acta Dermatovenero Croat 17: 279-284

32. Rasheed H, Mahgoub D, Hegazy R, El-Komy M, Abdel Hay R, et al. (2013) Serum ferritin and vitamin $D$ in female hair loss: Do they play a role? Skin Pharmacol Physiol 26: 101-107.

33. Le Guenno G, Chanséaume E, Ruivard M, Morio B, Mazur A (2007) Study of iron metabolism disturbances in an animal model of insulin resistance.
Diabetes Res Clin Pract 77: 363-370.

34. Kim OY, Baek SH, Lee YJ, Lee KH (2010) Association of increased hair calcium levels and enhanced augmentation index (Alx): a marker of arterial stiffness. Biol Trace Elem Res 138: 90-98.

35. Park SJ, Lee SH, Cho DY, Kim KM, Lee DJ, et al. (2013) Hair calcium concentration is associated with calcium intake and bone mineral density. Int J Vitam Nutr Res 83: 154-161.

36. Rashaid AH, Harrington PB, Jackson GP (2015) Profiling amino acids of jordanian scalp hair as a tool for diabetes mellitus diagnosis: a pilot study. Anal Chem 87: 7078-7084.

37. Kobayashi K, Igimi H (1996) Glycation index of hair for non-invasive estimation of diabetic control. Biol Pharm Bull 19: 487-490.

38. Oimomi M, Nishimoto S, Kitamura Y, Matsumoto S, Hatanaka H, et al. (1985) Increased fructose-lysine of hair protein in diabetic patients. Klin Wochenschr 63: $728-730$

39. Oimomi M, Matsumoto S, Maeda Y, Hata F, Nishimoto S, et al. (1987) Clinical application of the nonenzymatic glycation of hair protein in diabetic patients. J Japan Diab Soc 30: 367: 372

40. Shimode A, Yagi M, Naito J, Moniruzzaman M, Kaneko T, et al. (2014) Hair protein glycation reduces hair breaking strength. Glycative Stress Res 1: $37-$ 45.

41. Simopoulos AP (1991) Omega-3 fatty acids in health and disease and in growth and development. Am J Clin Nutr 54: 438-463.

42. Ellulu MS, Khaza'ai $H$, Abed $Y$, Rahmat A, Ismail $P$, et al. (2015) Role of fish oil in human health and possible mechanism to reduce the inflammation. Inflammopharmacology 23: 79-89.

43. Chen WJ, Yeh SL (2003) Effects of fish oil in parenteral nutrition. Nutrition 19 275-279.

44. Skolnik P, Eaglstein WH, Ziboh VA (1977) Human essential fatty acid deficiency: treatment by topical application of linoleic acid. Arch Dermatol 113: 939-941.

45. Schleicher ED, Wagner E, Nerlich AG (1997) Increased accumulation of the glycoxidation product $\mathrm{N}$ (epsilon)-(carboxymethyl)lysine in human tissues in diabetes and aging. J Clin Invest 99: 457-468.

46. Le Floch C, Cheniti A, Connétable S, Piccardi N, Vincenzi C, et al. (2015) Effect of a nutritional supplement on hair loss in women. J Cosmet Dermatol 14: 76-82. 